Al-Garnāți, Ibn 'Āṣim: El libro de los huertos en flor (hadā' iq al-azāhir). Cuentos, refranes $y$ anécdotas de la Granada nazarí. Traducción, estudio preliminar y notas de Desirée López BERNAL. Granada: Editorial Universidad de Granada, 20I9, 573 págs.

\title{
El libro de los huertos en flor
}

Francisco Moscoso GARCía

Universidad Autónoma de Madrid

El autor de El libro de los huertos en flor nació en Granada en I359, perteneció a una familia conocida de la vida política, judicial e intelectual del sultanato nazarí, se formó en la jurisprudencia y las letras, alcanzando un gran dominio tanto de la prosa como de la poesía, fue secretario y visir del sultán, pasó por la cárcel debido a las intrigas políticas, luego fue juez en Guadix y juez supremo en Granada, y murió en esta ciudad en I426. El género al que pertenece su obra hadā 'iq al-azāhir es el de $a d a b$ y fue dedicado al emir Yūsuf II. La editora explica que este género, en la época preislámica, era sinónimo de sunna, «conjunto de costumbres ancestrales, transmitidas oralmente de generación en generación» (p. 22). Y a partir del siglo VIII, comenzó a especializarse para servir a la enseñanza del «individuo culto (adīb) y refinado (zarīf)» (p. 23). Dentro de esta disciplina, había diferentes tipos de libros: manuales para formar a secretarios, centrados en los avaros - como el conocido Libro de los avaros de al-Ŷăhiz-, o de individuos inteligentes y tontos con una connotación humorística. Es en esta última línea de humor en la que se clasifica la obra de Ibn 'Āṣim (p. 23-24). No hay que olvidar que estos textos estaban escritos en la variedad árabe clásica y el escritor quería demostrar su dominio. Su comprensión solo estaba al alcance de aquellos que tuvieran competencias en árabe clásico, es decir, solo la élite.

La editora expone en su presentación de forma detallada las partes de las que se compone la obra, comenzando con el prólogo de Ibn 'Āṣim, en el que se explica «el proceso de composición y estructuración de su hadā 'iq al-azāhir» (p. 24). En este, Ibn 'Āṣim indica cuál es su objetivo:

Hay en él distracción para las almas, alivio para los espíritus y atracción para la alegría y los contentos; es el sosiego del corazón, el entretenimiento de quien asiste a las tertulias y a las veladas nocturnas, el regalo del que llega y las provisiones del viajero (p. 53).

El libro se compone de «seis huertos», divididos en capítulos, menos el cuarto. Son relatos narrativos, menos el quinto, que recoge una colección de 854 refranes traducidos de la lengua árabe nativa de los andalusíes, y algunos del árabe clásico. Los textos están escritos en esta última variedad y muchos de ellos incluyen versos. El resultado final es — según la autora - una obra que «transmite a quien se adentra en ella la sensación de estar armónica y equilibradamente ordenada» (p. 25). Además de esto, cabe destacar «la alternancia entre los contenidos serios como los más livianos» (p. 26), y la temática tan diversa: temas universales como la muerte o la enfermedad, algunos inmorales como la pederastia, el humor provocado por defectos físicos, temas de tipo sexual y escatológico, asuntos religiosos, etc. (p. 28-29).

Tres son los ejes de esta obra: anécdotas procedentes de la literatura árabe conocida como adab, cuentos y refranes de la Granada nazarí. Todo este mate- 
rial literario está recogido en la única obra en prosa del granadino Ibn 'Āṣim. La autora incluye al final de su edición un apéndice con los 44 cuentos que se recogen en El libro de los huertos, con su correspondiente clasificación en ATU (Aarne-Thompson-Uther). A este le sigue otro apéndice con aquellos textos «que constituyen cuentos folclóricos en el mundo árabe» (p. I2) y que están incluidos en las obras de Basset, Marzolph y El-Shamy. Sin embargo, hubiera sido preferible diferenciar los cuentos de las anécdotas. Por ejemplo, poner en el primer índice, el de la clasificación ATU, los cuentos que aparecen en las obras de estos tres autores y en el segundo índice solo anotar las anécdotas. El título de la obra de Basset, Mille et un contes, récits et légendes arabes, diferencia «cuento», «relato» $\mathrm{y}$ «legenda»; Marzolph habla en su título de «literatura de $a d a b$ », sin diferenciar los tipos de textos, y El-Shamy incluye en su título la voz folktale, término que engloba lo que Basset clasifica en su título.

La importancia de estos relatos recogidos en El libro de los huertos radica en tres aspectos. El primero tiene que ver con la transmisión de toda una literatura oral y escrita, recogida en los tratados de adab desde los inicios del islam, incluso poco antes, en época preislámica, de la que es heredera, tanto en forma como en contenido, la obra de Ibn 'Āṣim, y a la que se añadieron anécdotas que circulaban en al-Ándalus. El segundo, porque sirve de puente entre la tradición literaria árabe y la rica literatura del Siglo de Oro de nuestro país, gracias a la transmisión que de ella hacen los moriscos. Y el tercero, porque podemos seguir el rastro a los huertos en la rica literatura escrita y oral posterior a la caída de Granada en I492. Muchos judíos y moriscos tuvieron que exiliarse, por ejemplo, al norte de África, y con ellos trajeron el manuscrito de Ibn 'Āṣim, pero también una rica literatura oral transmitida de generación en generación a través de la lengua árabe materna o del castellano - este último es el caso de las comunidades judías en Marruecos de algunas ciudades del Norte-, que evolucionó a una variedad conocida como haquitía y que se habló en este país hasta los años setenta.

Las paremias contenidas en el capítulo $\mathrm{V}$ pueden ser rastreadas a partir del siglo XVI. Corriente y Bouzineb ${ }^{\mathrm{I}}$ han puesto de manifiesto la coincidencia de muchos de los refranes recopilados por el morisco granadino Alonso del Castillo y los de nuestro autor y Azzajjalī. A principios del siglo xıx en el Vocabulista del P. Patricio de la Torre ${ }^{2}$ se recogen 183 refranes, de los que 86 proceden de la obra de Ibn 'Āșim³. Y se podría rastrear la presencia de estos refranes entre las más de I8.ooo paremias recopiladas en 20 II en Marruecos por el grupo AMAPATRIL ${ }^{4}$. Claro que

I Cf. Federico Corriente; Hussein BouzineB: Recopilación de refranes andalusíes de Alonso del Castillo. Área de Estudios Árabes e Islámicos 3. Zaragoza: Universidad de Zaragoza, I994.

2 Cf. Francisco Moscoso García (ed.): Vocabulista castellano arábigo compuesto, y declarado en letra, y lengua castellana por el M. R. P. Fr. Pedro de Alcalá del orden de San Gerónimo. Corregido, aumentado, y puesto en caracteres arábigos por el P. Fr. Patricio de la Torre de la misma orden, Bibliotecario, y Catedrático de la lengua Arábigo-erudita en el Rl. Monasterio de Sn. Lorenzo del Escorial, y profeso en él. Año de I805. Libros de la Isla 2. Cádiz: Editorial UCA y UCOPress, 2018. 3 Cf. Francisco Moscoso García: «Los refranes recogidos en el Vocabulista del P. Patricio de la Torre: puente de unión entre al-Andalus y Marruecos». Boletín de Literatura Oral vol. Io (2020): I7I-2I7.

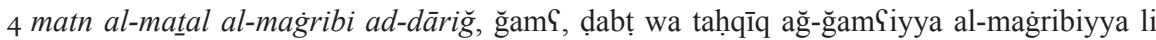
t-turāt al-lugiawi, AMAPATRIL, ar-Ribāṭ, maṭū̧āat akādīmiyya al-mamlaka al-magribiyya, silsila at-turāt, $201 \mathrm{I}$. 
muchas de estas podrían haber llegado a al-Ándalus y sobrevivir en muchos países árabes sin que hubieran llegado de vuelta. Lo mismo podríamos decir de los cuentos en muchas de las recopilaciones que se han llevado a cabo, no solo la de Basset. Por ejemplo, entre los I 28 cuentos $^{5}$ que se recogen en la obra Dictons et traditions ${ }^{6}$ del P. Yves Alliaume, que fueron recopilados en árabe del Sáhara argelino entre I926 y I978 en distintas localidades de esta vasta región, hay cinco que están en El libro de los huertos.

La edición final que ha hecho la autora es merecedora de tener en cuenta. Ha presentado, en primer lugar, los manuscritos y ediciones existentes, así como las traducciones parciales (p. 29-32). Las notas a pie de página, un total de I.328, son indispensables para entender los relatos en muchos de sus pasajes. Primero, por la cantidad de personajes que la autora ha reseñado debidamente, situándolos en su contexto. En este sentido, cabe destacar el índice onomástico tan extenso y completo que incluye al final del libro. Le siguen otros dos índices con nombres de tribus y linajes y toponímico. Son igualmente interesantes las aclaraciones sobre el léxico especializado — nombres de comida, términos administrativos, religiosos, etc.-, cuyo índice completo se recoge también al final. Quizá hubiera sido necesario que aquí pusiera la traducción de cada uno de ellos, ya que, al leer los textos, la autora solo coloca la traducción y una explicación detallada en nota a pie de página la primera vez que aparecen. Y, por último, hay muchas más indicaciones que hacen la lectura de los textos bastante comprensiva para un lector que no conozca la lengua árabe. Entre ellas cabe destacar algunos términos, préstamos del romance al árabe andalusí, que la autora ha mantenido y comentado convenientemente: duš, «dos», fidawš, «fideos» (p. I84-I85).

Hay referencias a la época preislámica, a los imperios bizantino y persa, a Alejandro Magno, a los califas ortodoxos, a califas omeyas y abasíes - entre estos, Hārūn al-Rašīd-, a Jesús y a algunos apóstoles o a Juan el Bautista, a coptos, a griegos, a los hijos del cuarto califa ortodoxo, Alí, a poetas como Abū Nuwās y alMutanabbī — considerados grandes poetas por los árabes_-, a los creadores de las escuelas jurídicas, como Abū Hanīfa, a figuras religiosas como el almuédano ${ }^{7}$, al zejelero andalusí Ibn Quzmān, al autor del Libro de los avaros, al-Ŷāḥiz, a las ciudades de Kufa, Basora, Medina, La Meca, Bugía, Sevilla o Granada, a cuentacuentos, a gramáticos, a beduinos, a gorrones, avaros, al vino, etc. La lista sería intermina-

Amapatril: Association marocaine du patrimoine linguistique. La recopilación de los refranes ha sido hecha por sus integrantes: Zakia Iraqui Sinaceur, Abderrahim Youssi, Fouzia Benjelloun, Hafida Lamrani, Mohamed Dahbi y Abdelhaq Cherradi.

5 Francisco Moscoso GARcía: Cuentos del Sáhara argelino recogidos por el P. Yves Alliaume. Estudio y edición bilingüe árabe argelino del Sáhara-español de los textos. Textos semíticos, Arabica. Córdoba: UCOPress (en prensa).

6 Cf. Francisco Moscoso GARCÍA: «Dichos y tradiciones: Literatura oral y orientalismo católico en el Sáhara argelino (I926-I975)». Boletín De Literatura Oral anejo 2 (2O2O): I-III4, DOI: https://doi.org/IO.I756I/blo.vanejoi2

7 Sobre este personaje hay un cuento en la edición con el número 455 (p. I8I), que está clasificado en ATU con el número I730. La imagen del almuédano que se enamora de una mujer, porque la ve en la terraza de su casa desde lo alto del alminar, es recurrente en otros cuentos del mundo árabe. Véase el cuento zarqa w marqa (ATU 883B) en Francisco Moscoso García: Aproximación al cuento narrado en árabe marroquí. Suomalaisen Tiedeakatemian Toimituksia Humaniora 362. Helsinki: Annales Academiæ Scientiarum Fennicæ, 2012. 
Reviews

ble. Sí nos gustaría resaltar la presencia de $\hat{Y} u{ }^{2} \bar{a}^{8}$, de quien valdría la pena ver si muchas de las historias que se cuentan de él en la cuenca mediterránea se corresponden con los textos en los que aparece su figura o en otros que no.

La edición de El libro de los huertos en flor llevada a cabo por Desirée López Bernal es, en su conjunto, una gran contribución para conocer la literatura andalusí en su última etapa peninsular y constituye un material de investigación primordial para seguir el rastro de esta producción tanto en España, en la literatura del Siglo de Oro, como en el mundo árabe en general, y de la región de Magreb en particular.

8 Sobre este personaje, $c f$. Tomás García Figueras: Cuentos de Yehá. Sevilla: Padilla libros, 1989, y Clara María Thomas de Antonio: «Ŷ̀uhā, un personaje popular en el Magreb y en todo el mundo árabe». al-Andalus-Magreb núm. I (1993): 187-223. 